\title{
A ORGANIZAÇÃO DO TRABALHO PEDAGÓGICO NO ESPACO DO ATENDIMENTO EDUCACIONAL ESPECIALIZADO
}

\author{
THE ORGANIZATION OF PEDAGOGICAL WORK IN THE SPACE \\ OF THE SPECIALIZED EDUCATIONAL ATTENDANCE \\ LA ORGANIZACIÓN DEL TRABAJO PEDAGÓGICO EN EL ESPACIO \\ DEL ATENCIÓN EDUCATIVA ESPECIALIZADA
}

Jane Claro Bernardo*

(i) https://orcid.org/oooo-0oo1-5857-673X

Geandra Cláudia Silva Santos**

(iD) https://orcid.org/oooo-0oo2-7782-6316

\begin{abstract}
REVISTA PEDAGÓGICA
Revista do Programa de Pós-graduação em Educação da Unochapecó | ISSN 1984-1566

Universidade Comunitária da Região de Chapecó | Chapecó-SC, Brasil Como referenciar este artigo: BERNARDO, J. C.; SANTOS, G. C. S. A organização do trabalho pedagógico no espaço do atendimento educacional especializado. Revista Pedagógica, Chapecó, v. 22, p. 1-25, 2020. DOI: http://dx.doi.org/10.22196/rp.v22io.4570
\end{abstract}

Resumo: Esse estudo objetiva compreender a organização do trabalho pedagógico do atendimento educacional especializado por meio da análise das produções acadêmicas brasileiras, publicadas no período de 2008 a 2013. Para isso, foi realizada a pesquisa bibliográfica nos bancos de Teses e Dissertações de algumas universidades, em Anais de Congressos Brasileiros e em Periódicos Eletrônicos. Foram selecionadas as produções que tinham relação com a temática de investigação mencionada e, posteriormente, procedeu-se a análise e discussão dos trabalhos selecionados. Os resultados da análise apontaram alguns avanços nas ações educativas examinadas, contudo a maioria dos estudos analisados apontou a existência de problemas na organização do atendimento educacional especializado que implicam no funcionamento do serviço e em sua qualidade.

Palavras-chave: Atendimento Educacional Especializado. Educação Especial. Educação Inclusiva.

Abstract: This study aims to understand the organization of the pedagogical work of the specialized educational service through the analysis of Brazilian academic productions, published in the period from 2008 to 2013. For this, the bibliographic research was carried out in the banks of Theses and Dissertations of some universities, Annals of Brazilian Congresses and Electronic Periodicals. The productions that were related to the mentioned research topic were selected and, later, the selected works were analyzed and discussed. The results of the analysis have pointed out some advances in the examined educational actions, however the majority of studies analyzed pointed out the existence of problems in the organization of the specialized educational service which imply in the operation of the service and its quality.

Keywords: Specialized Educational Assistance. Special education. Inclusive education.

Resumen: Este estudio tiene como objetivo comprender la organización del trabajo pedagógico de la atención educativa especializada por medio de la análisis de las producciones académicas brasileñas, publicadas en el período de 2008 a 2013. Para ello, se realizó la investigación bibliográfica en los bancos de datos Tesis y Disertaciones de algunas universidades, en Anales de Congresos Brasileños y en Periódicos Electrónicos. Se seleccionaron las producciones que tenían relación con la temática de investigación mencionada y posteriormente se procedió el análisis y discusión de los trabajos seleccionados. Los resultados del análisis señalan algunos avances en las acciones educativas examinadas, sin embargo, la mayoría de los estudios analizados apuntó la existencia de problemas en la organización de la atención educativa especializada que implican en el funcionamiento del servicio y en su calidad.

Palabras clave: Atención Educativa Especializada. Educación Especial. Educación inclusiva. 


\section{Introdução}

Nos últimos anos, foi possível observar a ampliação do debate sobre a educação inclusiva no Brasil, tema que conquistou espaço nos discursos nos âmbitos político, educacional e social. A ampliação dessa perspectiva educacional em nível mundial com impacto significativo na realidade brasileira é fruto de uma luta histórica dos movimentos sociais, das entidades nacionais e internacionais e de tantas outras pessoas que têm se empenhado em favor da garantia dos direitos das pessoas com necessidades educacionais especiais (NEE).

A criação de leis e de documentos que favorecem a inclusão social e educacional das pessoas com NEE, em nível internacional, foi impulsionada pelas Declaração Universal dos Direitos Humanos, aprovada pela Organização das Nações Unidas (ONU) e pela Declaração de Salamanca, dentre outros documentos importantes de caráter político, que influenciaram leis, políticas e programas em vários países, a exemplo do que ocorreu no Brasil.

Em 1996, a Lei de Diretrizes e Bases da Educação Nacional - LDB no 9.394/96 definiu a educação especial como uma modalidade de educação escolar que deve ser ofertada, preferencialmente, na rede regular de ensino para os alunos com NEE. Em 2008, a aprovação da Política Nacional de Educação Especial na Perspectiva da Educação Inclusiva (PNEEPEI) representou um grande avanço na luta por uma educação especial inclusiva no país, pois estabeleceu, ao direcionar a implantação, a organização e o funcionamento do Atendimento Educacional Especializado (AEE) nas escolas, como um dos serviços que devem ser garantidos aos alunos público-alvo da educação especial. O AEE tem como função a organização de recursos como equipamentos, materiais didáticos e pedagógicos que ajudem no rompimento de barreiras que promovam a acessibilidade à escola (BRASIL, 2008).

Considerando a importância atribuída ao AEE nos marcos regulatórios recentes da educação especial por representar uma ferramenta central para a realização da educação inclusiva, surgiu o interesse em estudar a realidade desse atendimento, a partir da literatura científica produzida. Assim, definimos como objetivo central deste estudo compreender a organização do trabalho pedagógico do atendimento educacional especializado, por meio da análise das produções acadêmicas brasileiras, publicadas no período de 2008 a 2013.

A relevância desse estudo está no fato de entendermos que o AEE foi criado com o intuito de propiciar o processo de inclusão dos alunos com NEE no sistema regular de ensino, e que assim é importante conhecer como esse
* Graduada em Pedagogia pela Universidade Estadual do Ceará (UECE). Membro do Grupo de Pesquisa Educação Especial na mesma instituição.

E-mail: jane_clarobernardo@hotmail.com

** Doutora em Educação pela Universidade de Brasília-(UnB). Professora do Curso de Pedagogia e do Programa de Pós-Graduação em Educação - (PPGE) da Universidade Estadual do Ceará -(UECE).

E-mail: geandra.santos@uece.br 
serviço tem se efetivado na prática, ou seja, se a forma como vem sendo organizado tem realmente possibilitado a inclusão, segundo a literatura produzida na área, a partir da publicação da PNEEPEI.

Vale destacar que o presente artigo é um recorte de um trabalho resultante da elaboração do trabalho de conclusão de curso de graduação no curso de Pedagogia. A escolha do tema surgiu a partir de uma experiência como bolsista de iniciação científica (Programa de Bolsas de Iniciação Científica - PIBIC, financiado pelo CNPq) em que realizamos estudos na área da educação inclusiva, integrante de uma pesquisa mais ampla desenvolvida em uma universidade pública que tinha como campo de estudo o AEE.

Desse modo, neste artigo apresentamos breve discussão teórica sobre o surgimento e desenvolvimento da perspectiva da educação inclusiva no Brasil, com intuito de contextualizar o objeto de estudo. Em seguida, apresentamos os caminhos metodológicos percorridos para a realização do estudo e a discussão sobre os achados da pesquisa, por meio da análise dos trabalhos mapeados e selecionados.

\section{Educação Especial Inclusiva: fundamentos e marcos legais}

A perspectiva da educação inclusiva começou a ser expandida entre o final do século XX e início do século XXI, tendo influência dos discursos de democratização da escola e universalização da educação básica, que apontavam para a necessidade de um novo projeto educacional em que o acesso à educação fosse garantido para todos, considerando a expansão do acesso à escola como uma forma de inclusão social das minorias que, até então, não tinham oportunidades educacionais e sociais.

Essa perspectiva teve um maior avanço em âmbito mundial, a partir da Conferência Mundial sobre Educação Especial, realizada em Salamanca, na Espanha, em 1994, que teve por objetivo "[...] fornecer diretrizes básicas para a formulação e reforma de políticas e sistemas educacionais de acordo com o movimento de inclusão social" (MENEZES; SANTOS, 2001, p.01).

Esse documento representa um marco muito importante para a educação porque ampliou a discussão mundial sobre a importância de se adotar o modelo de educação inclusiva que consiste na inserção de todos os alunos na escola, independente de quaisquer dificuldades ou diferenças que possam ter.

No Brasil, os caminhos para a incorporação da perspectiva da educação inclusiva seguiram um processo 
lento, conforme observamos na legislação brasileira que rege o campo educacional. Nesse sentido, é possível perceber alguns sinais de avanços a favor da proposta inclusiva, a partir da promulgação da Constituição Federal, em 1988, que traz como um dos seus objetivos fundamentais, no art. $3^{\mathrm{o}}$, inciso IV: "Promover o bem de todos, sem preconceitos de origem, raça, sexo, cor, idade e quaisquer outras formas de discriminação" (BRASIL, 2008, p.10). O artigo 205 estabelece que:

A educação, direito de todos e dever do Estado e da família, será promovida e incentivada com a colaboração da sociedade, visando ao pleno desenvolvimento da pessoa, seu preparo para o exercício da cidadania e sua qualificação para o trabalho (BRASIL, 1988, p. 34).

$\mathrm{O}$ artigo 206, Inciso I define como um dos princípios para o ensino "A Igualdade de condições para o acesso e permanência na Escola" (BRASIL, 1988, p.34), e no artigo 208, Inciso III, garante como dever do Estado: "O atendimento educacional especializado aos portadores de deficiência, preferencialmente, na rede regular de ensino" (BRASIL, 1988, p. 35). A Constituição, ao definir esses direitos e princípios para as pessoas com NEE, de certa forma, defende um posicionamento favorável à inclusão educacional de todas as pessoas, quando a luta pela educação inclusiva ainda estava sendo deflagrada fora do país.

Em 1994, foi lançada a Política Nacional de Educação Especial. Esse documento, de acordo com Dutra e Santos:

[...] define como modalidades de atendimento em educação especial no Brasil: as escolas e classes especiais; $\mathrm{o}$ atendimento domiciliar, em classe hospitalar e em sala de recursos; o ensino itinerante, as oficinas pedagógicas e a estimulação essencial; e as classes comuns. Mantendo a estrutura paralela e substitutiva da educação especial [....] (DUTRA; SANTOS, 2010, p. 21).

O Brasil lançou esse documento no mesmo ano em que foi lançada a Declaração de Salamanca, e ao compararmos as diretrizes da Declaração de Salamanca com as definições dessa Política, percebemos a distância que o país estava em relação ao acompanhamento das mudanças propostas para o campo educacional, em nível mundial, que apontavam para a necessidade da construção de sistemas educacionais inclusivos.

Em 1996 foi promulgada a atual LDB, Lei nº 9394/96 que incluiu o capítulo V específico sobre a educação especial, estabelecendo-a como uma modalidade de educação 
escolar. O artigo 59 estabelece que os sistemas de ensino assegurarão aos educandos com necessidades especiais: "currículos, métodos, técnicas, recursos educativos e organização específicos, para atender às suas necessidades” (BRASIL, 1996), dentre outros recursos materiais e humanos destinados para esse fim.

Essa lei, ao mesmo tempo em que contribui para que os alunos com NEE se matriculem no sistema regular de ensino, mantém a possibilidade do atendimento educacional especializado substitutivo à escolarização, quando afirma oferta preferencial e não obrigatória na rede regular de ensino (DUTRA; SANTOS, 2010).

Assim, é somente no ano de 2008 que o Brasil tem seu maior alinhamento com a proposta de educação inclusiva, com a publicação, pelo Ministério da Educação (MEC), da nova Política Nacional de Educação Especial na Perspectiva da Educação Inclusiva. Essa política avança porque objetiva gerar o acesso ao ensino regular para os alunos com NEE, buscando garantir o apoio necessário para promover a aprendizagem e o desenvolvimento desses alunos. Segundo Dutra e Santos, “[...] essa nova política instaura um novo marco teórico e organizacional na educação brasileira, definindo a educação especial como modalidade não substitutiva à escolarização" (DUTRA; SANTOS, 2010, p. 22), apontando o AEE como um dos serviços que deve ser garantido aos alunos com NEE.

O AEE foi regulamentado pelo Decreto $\mathrm{n}^{0}$ 6.571, de 2008, que reestrutura a educação especial, destina recursos para ampliar a oferta desse serviço na rede pública de ensino regular. Também definiu o Atendimento Educacional Especializado, no art. $1^{\mathrm{o}}, \S 1^{\mathrm{\Omega}}$, como: “[...] o conjunto de atividades, recursos de acessibilidade e pedagógicos organizados institucionalmente, prestado de forma complementar ou suplementar à formação dos alunos no ensino regular". (BRASIL, 2008, p. 01). Assim, com as determinações deste decreto, $\mathrm{o}$ atendimento educacional para as pessoas com NEE deve ser realizado no sistema regular de ensino, sendo garantido o acesso ao AEE no turno inverso à escolarização.

Percebemos o quanto a perspectiva da educação inclusiva é recente no Brasil. No entanto, tem provocado mudanças no funcionamento do atendimento educacional para as pessoas com NEE, embora o país ainda não tenha realizado mudanças significativas em favor dessa proposta. Igualmente, compreendemos que a caminhada ainda é longa, até o país construir um processo educacional que se aproxime da inclusão preconizada, pois o fato das pessoas com NEE terem conquistado o direito à educação nos dispositivos legais e aparatos teóricos e estarem participando do sistema regular de ensino não significa que elas estejam incluídas. 


\section{Caminhos Metodológicos}

Fundamentado na pesquisa qualitativa, o presente estudo caracteriza-se como pesquisa bibliográfica porque busca, mediante levantamento bibliográfico, descrever a organização do trabalho pedagógico do atendimento educacional especializado, como também analisar se essa organização tem favorecido o processo de inclusão escolar dos alunos com NEE. Segundo Nóbrega (2006, p. 80), “a pesquisa bibliográfica é de natureza teórica e busca soluções para o problema por meio dos aportes teóricos, ou seja, de material já elaborado; possibilita o embasamento teórico fundamental para a abordagem reflexiva e crítica”.

O levantamento bibliográfico foi realizado nos bancos de teses e dissertações de algumas universidades que possuem curso ou programa de formação na área da educação especial, em anais de congressos brasileiros e em revistas científicas eletrônicas. Assim, realizamos a busca por artigos científicos, dissertações e teses publicadas no período de 2008 a 2013, à procura de identificarmos trabalhos diretamente relacionados com a temática de investigação ou que se aproximasse dela. Para acessarmos os trabalhos nas bases de dados selecionadas, utilizamos algumas palavras-chave que funcionam como indexadores: Educação Especial, Educação Inclusiva, Atendimento Educacional Especializado, Necessidades Educacionais Especiais, Sala de Recursos Multifuncionais, Sala de Educação Especial.

A seleção dos trabalhos, durante o levantamento, foi realizada por meio da leitura de todos os títulos e resumos dos trabalhos. Dentre os trabalhos selecionados, procedemos à leitura do trabalho completo ou parcial, porque nem todos os resumos permitiram identificar o objeto de estudo e suas especificações.

O quadro 01, a seguir, ilustra a quantidade de trabalhos encontrados nas bases de dados acessadas e a relação entre as produções científicas identificadas por meio dos indexadores e a quantidade de trabalhos relacionados à temática em estudo. Para a construção desse quadro, utilizamos os seguintes critérios: para quantificar o total de trabalhos identificados, indicamos, na primeira coluna, o nome das bases de dados pesquisadas; na segunda coluna, indicamos o número de trabalhos que apareceram, a partir das palavras-chave digitadas no campo de busca de cada base de dados acessada; na terceira coluna, indicamos a quantidade de trabalhos que apresentam a maior relação com a temática em estudo; na quarta coluna estão as porcentagens correspondentes às quantidades de trabalhos identificados com a temática central do estudo. Isso foi necessário, porque, para cada palavra-chave utilizada, aparecem quantidades de trabalhos específicas. 
Quadro o1. Quantidade geral de trabalhos identificados nas bases de dados

\begin{tabular}{|l|c|c|c|}
\hline Bases de Dados & Achados & Relação com a temática & $\mathbf{\%}$ \\
\hline Domínio Público/Capes & 13 & 03 & 23,0 \\
\hline Universidade Federal Santa Maria & 1040 & - & - \\
\hline Revista Brasileira de Educação Especial & 226 & 02 & 0,88 \\
\hline Revista Educação Especial/Capes & 08 & 01 & 12,5 \\
\hline Anais do C. B. M. de E. Especial - UEL & 451 & 04 & 0,88 \\
\hline BDTD & 500 & 04 & 0,8 \\
\hline Universidade Estadual de Londrina & 164 & 03 & 1,8 \\
\hline ANPED & 101 & 04 & 3,9 \\
\hline Programa de Pós Graduação em Educação- UECE & 105 & 01 & 0,95 \\
\hline Banco de Teses e Dissertações/Capes & 89 & 03 & 3,3 \\
\hline Google Acadêmico & 30 & $\mathbf{2 5}$ & - \\
\hline Total & $\mathbf{2 7 2 7}$ & & $\mathbf{0 , 9 1}$ \\
\hline
\end{tabular}

Fonte: Elaboração própria

No caso das bases de dados Domínio Público/CAPES, Revista Educação Especial/CAPES, Universidade Estadual de Londrina e o Banco de teses e dissertações da CAPES, a palavra-chave que permitiu a identificação do maior número de trabalhos relacionados à temática de interesse foi Atendimento Educacional Especializado.

Nas bases de dados Revista Brasileira de Educação Especial/SCIELO e a Biblioteca Digital Brasileira de Teses e Dissertações/BDTD a palavra-chave com maiores achados foi Educação Especial.

No caso do banco de teses e dissertações da Universidade Federal de Santa Maria, foi utilizado, para a quantificação dos trabalhos, o total de produções que apareceu com a palavra-chave Educação Especial, haja vista não termos identificado textos com outros indexadores. $\mathrm{O}$ caso se repetiu na base de dados Google Acadêmico, sendo utilizado a palavra-chave Sala de Recursos Multifuncionais.

Com relação ao Programa de Pós-Graduação em Educação da UECE foi desnecessária a utilização de indexador, pois o programa disponibiliza os trabalhos de todas as áreas em agrupamento único, além de registrar, à época, poucas produções disponíveis. Assim, utilizamos o total de trabalhos que estavam disponíveis no banco de dissertações.

No caso dos Anais do Congresso Brasileiro Multidisciplinar de Educação Especial - Universidade Estadual de Londrina - fizemos a busca dos trabalhos pelos anos de realização do evento, que é bienal. Sendo assim, consideramos os anos 2009, 2011 e 2013. No ano de 2009, todos os trabalhos estavam disponibilizados em agrupamento único. A partir dos anos seguintes houve a divisão dos trabalhos em subtemas, sendo chamados de área temática. Desse 
modo, para quantificarmos os trabalhos encontrados nesses Anais, utilizamos o total de trabalhos do ano de 2009 e nos anos 2011 e 2013 utilizamos o total de trabalhos que apareceram dentro dos subtemas relacionados à temática em foco: Área temática 04, Educação, reabilitação, deficiência e novas tecnologias; Área temática 06, A pessoa com deficiência no contexto do trabalho; Área temática 11, Altas Habilidades/Superdotação identificação e intervenção; Área temática 14, Serviços de educação especial.

No caso da ANPED, analisamos a partir da $31^{\mathrm{a}}$ até a $36^{\mathrm{a}}$ reunião nacional que corresponde ao período de 2008 a 2013. Verificamos os trabalhos disponibilizados no GT 15 Educação Especial a cada ano.

Dos trabalhos encontrados nas bases de dados banco de Teses e Dissertações da CAPES e no BDTD relacionados à temática, 06 trabalhos encontram-se cadastrados nas duas bases de dados. Com isso, decidimos mencioná-los uma vez.

Ao final, o levantamento bibliográfico realizado nos possibilitou identificar 25 estudos relacionados à temática investigada, os quais serão analisados e discutidos a seguir.

\section{A organização do trabalho pedagógico do atendimento educacional especializado na produção acadêmica brasileira}

Os 25 estudos mapeados que têm relação direta com a temática Organização do trabalho pedagógico do Atendimento Educacional Especializado, estão organizados no quadro 02, a seguir, com a identificação de autor, ano, tema central e objetivo geral dos trabalhos selecionados.

Quadro 2: Informações sobre os trabalhos selecionados

\begin{tabular}{|l|l|l|}
\hline Autor/Ano & Tema Central & Objetivo \\
\hline CHIESA, 2009 & AEE & $\begin{array}{l}\text { Analisar os indícios da história da implantação das salas de recursos } \\
\text { multifuncionais e como acontece a oferta do atendimento educacional } \\
\text { especializado nesses espaços. }\end{array}$ \\
\hline SILVA, 2009 & $\begin{array}{l}\text { Sala de Recursos } \\
\text { Multifuncionais } \\
\text { (SRM) }\end{array}$ & $\begin{array}{l}\text { Conhecer e analisar os tipos de apoios prestados na Sala de Recursos a alunos } \\
\text { com necessidades educacionais especiais e a seus professores das classes } \\
\text { comuns. }\end{array}$ \\
\hline $\begin{array}{l}\text { GALVÃO E } \\
\text { MIRANDA, 2012 }\end{array}$ & AEE & $\begin{array}{l}\text { Analisar e discutir as diferentes formas de Atendimento Educacional } \\
\text { Especializado, prestadas aos alunos com surdocegueira. }\end{array}$ \\
\hline BAGGIO, 2010 & Educação & $\begin{array}{l}\text { Mostrar como está estruturado o trabalho de uma escola do município de } \\
\text { Cristalina-GO, na perspectiva da educação inclusiva, observando a colaboração } \\
\text { do gestor e do coordenador e a atuação do professor frente a esta nova proposta } \\
\text { pedagógica. }\end{array}$ \\
\hline $\begin{array}{l}\text { MORI; BRANDÃO, } \\
\text { 2009 }\end{array}$ & Educação Especial \\
\hline $\begin{array}{l}\text { DELPRETTO; } \\
\text { SANTOS, 2013 }\end{array}$ & $\begin{array}{l}\text { Conhecer o atendimento educacional realizado em Salas de Recursos para alunos } \\
\text { com Altas Habilidades/Superdotação (AH/SD) no Estado do Paraná. }\end{array}$ \\
\hline
\end{tabular}




\begin{tabular}{|c|c|c|}
\hline Autor/Ano & Tema Central & Objetivo \\
\hline $\begin{array}{l}\text { MORETI; CORRÊA, } \\
2009\end{array}$ & Sala de Recursos & $\begin{array}{l}\text { Analisar o papel da sala de recursos para alunos com deficiência mental, } \\
\text { 'incluídos' em classes comuns de uma escola municipal de Campo Grande - MS. }\end{array}$ \\
\hline BENTES, 2011 & Educação Inclusiva & $\begin{array}{l}\text { Investigar como são efetivadas as práticas de escolarização inclusiva nas salas } \\
\text { de recursos multifuncionais em escolas públicas de um município paraense da } \\
\text { grande Belém. }\end{array}$ \\
\hline $\begin{array}{l}\text { PORTO; } \\
\text { MARQUEZINE, } \\
2013\end{array}$ & $\mathrm{AEE}$ & $\begin{array}{l}\text { Analisar a organização e o funcionamento da Sala de Recursos Multifuncional, } \\
\text { tendo-se como amostragem dados coletados em uma SRM da rede estadual de } \\
\text { ensino do Paraná. }\end{array}$ \\
\hline $\begin{array}{l}\text { CARDOSO; } \\
\text { TARTUCI, } 2013\end{array}$ & AEE & $\begin{array}{l}\text { Analisar o funcionamento espacial, temporal e distribuição de alunos no AEE } \\
\text { e, as práticas pedagógicas a serem realizadas nesse atendimento, com foco no } \\
\text { planejamento do professor para a organização desse serviço. }\end{array}$ \\
\hline MACHADO, 2013 & AEE & $\begin{array}{l}\text { Conhecer o que o AEE, como nova perspectiva e prática da Educação Especial, } \\
\text { provocou de mudanças nas percepçóes e atuações dos gestores e professores das } \\
\text { escolas municipais de Florianópolis. }\end{array}$ \\
\hline MILANESI, 2012 & $\begin{array}{l}\text { Sala de Recursos } \\
\text { Multifuncionais }\end{array}$ & $\begin{array}{l}\text { Descrever e analisar os serviços das SRM de um município do interior de Estado } \\
\text { de São Paulo, a fim de entender como esses estão sendo organizados para } \\
\text { atender aos dispositivos legais sobre a implantação do AEE. }\end{array}$ \\
\hline DELEVATI, 2012 & AEE & $\begin{array}{l}\text { Analisar as configurações do Atendimento Educacional Especializado (AEE) na } \\
\text { Rede Municipal de Ensino de Gravataí/RS. }\end{array}$ \\
\hline SOARES, 2011 & $\mathrm{AEE}$ & $\begin{array}{l}\text { Descrever e analisar o Atendimento Educacional Especializado oferecido aos } \\
\text { alunos surdos em uma escola municipal de ensino médio }\end{array}$ \\
\hline LYRA, 2013 & Educação Especial & $\begin{array}{l}\text { Analisar como tem sido realizado o atendimento de alunos com Altas/ } \\
\text { Habilidades e Superdotação na rede pública estadual de ensino, da região } \\
\text { metropolitana de Londrina. }\end{array}$ \\
\hline LOPES, 2010 & Educação Especial & $\begin{array}{l}\text { Analisar como vinham sendo processados a inclusão do aluno com deficiência } \\
\text { intelectual no ensino regular e o AEE nos serviços da rede de apoio ofertado por } \\
\text { uma escola no estado do Paraná. }\end{array}$ \\
\hline CORRÊA, 2013 & Educação Especial & $\begin{array}{l}\text { Analisar a avaliação, o diagnóstico e o encaminhamento de crianças com } \\
\text { necessidades educacionais especiais, na Rede Municipal de Ensino de Londrina, } \\
\text { a partir da nova estrutura da educação especial do Município. }\end{array}$ \\
\hline SILVA, 2011 & $\mathrm{AEE}$ & $\begin{array}{l}\text { Investigar o processo de inclusão de alunos com Deficiência Intelectual (DI), } \\
\text { no contexto do Atendimento Educacional Especializado (AEE) e da sala de aula } \\
\text { regular, evidenciando as possíveis relações entre ambos. }\end{array}$ \\
\hline BARBOSA, 2012 & AEE & $\begin{array}{l}\text { Analisar as diferentes concepções dadas à educação especial nas últimas décadas } \\
\text { e verificar se as orientações da atual Política Nacional de Educação Especial em } \\
\text { relação ao AEE concorrem para a exequibilidade desse serviço na perspectiva da } \\
\text { educação inclusiva. }\end{array}$ \\
\hline PADILHA, 2013 & $\begin{array}{l}\text { Educação } \\
\text { Especial }\end{array}$ & $\begin{array}{l}\text { Situar os professores de EE nas questões concernentes à docência enquanto } \\
\text { trabalho concreto, refletindo sobre o que fazem e em quais relações e condições } \\
\text { esse trabalho se constitui na rede estadual de SP. }\end{array}$ \\
\hline FONTES, 2012 & AEE & $\begin{array}{l}\text { Investigar a respeito de como estaria acontecendo, de fato, a implantação do } \\
\text { programa de implantação de salas de recursos multifuncionais e o seu impacto } \\
\text { no Ensino Regular no Município de Porto Velho } \backslash \text { RO. }\end{array}$ \\
\hline SPERB, 2012 & AEE & $\begin{array}{l}\text { Analisar como professores entendem a proposta do AEE e como esse } \\
\text { atendimento ocorre em escolas do Rio Grande do Sul segundo professores e } \\
\text { alunos surdos. }\end{array}$ \\
\hline $\begin{array}{l}\text { CHRISTOFARI; } \\
\text { FREITAS; TEZZARI, } \\
2012\end{array}$ & AEE & $\begin{array}{l}\text { Responder à pergunta fundante do estudo: Como o AEE vem produzindo modos } \\
\text { de articular o fazer pedagógico tendo em vista a sustentação e aprendizagem de } \\
\text { alunos referidos como tendo Deficiência, Transtorno Global do Desenvolvimento } \\
\text { e Altas Habilidades nas salas de aula do ensino comum. }\end{array}$ \\
\hline MELETTI, 2009 & Educação Especial & $\begin{array}{l}\text { Analisar a estrutura e o funcionamento da Educação Especial nas escolas } \\
\text { regulares da rede Municipal de Ensino de Londrina - PR. }\end{array}$ \\
\hline BRIDI, 2012 & AEE & $\begin{array}{l}\text { Conhecer como ocorrem os processos de identificação e diagnóstico dos alunos } \\
\text { com deficiência mental no contexto do Atendimento Educacional Especializado. }\end{array}$ \\
\hline
\end{tabular}

Fonte: Elaboração própria

Os estudos apresentados foram lidos criteriosamente, analisados e confrontados na busca de identificarmos semelhanças e divergências entre as informações registradas nas produções selecionadas a respeito da organização do 
trabalho pedagógico do AEE. Elegemos as informações mais significativas, tendo em conta a relevância atribuída na configuração da realidade investigada e sua recorrente menção nos trabalhos. Essas informações convergiram para a definição de aspectos importantes na tessitura complexa da organização do AEE na escola, em discussão a seguir.

\section{Articulação entreensino comum e atendimento educacional especializado}

As Diretrizes Operacionais para o Atendimento Educacional Especializado na Educação Básica, no artigo 13, Inciso VIII, determinam como uma das atribuições do professor do AEE: "Estabelecer articulação com os professores da sala de aula comum, visando à disponibilização dos serviços, recursos pedagógicos e de acessibilidade e das estratégias que promovam a participação dos alunos nas atividades escolares" (BRASIL, 2009, p.03).

A importância da articulação entre o ensino comum e o AEE para o processo de inclusão dos alunos com NEE está no fato de poderem desenvolver um trabalho colaborativo, com a finalidade de compartilhar saberes e experiências; pensar juntos ações para construírem alternativas pedagógicas que contribuam para a inclusão dos alunos, identificando limites e possibilidades; criar estratégias e materiais didáticos adequados aos alunos com NEE; avaliar e acompanhar o desenvolvimento dos alunos no percurso escolar, dentre outros.

No que pese a importância da articulação entre ensino comum e o AEE, em 10 trabalhos dos 25 analisados, constataram dificuldades relacionadas à concretização de uma prática calcada na articulação entre os profissionais. São várias as causas identificadas pelos autores como entraves para a efetivação da relação entre o ensino comum e o AEE na organização do serviço. Os trabalhos de Moreti e Corrêa (2009), Silva (2009), Meleti (2009), Delevati (2012), Barbosa (2012) identificaram como uma das dificuldades o fato das salas de recursos multifuncionais atenderem alunos de outras escolas, em virtude de muitas instituições não disporem do AEE em suas dependências. Os trabalhos de Meleti (2009) e Barbosa (2012) apontaram outras dificuldades: a resistência de alguns professores do ensino comum ao trabalho do professor do AEE e a total responsabilização desse profissional com vistas à escolarização dos alunos com NEE.

Os trabalhos de Porto e Marquezine (2013) e Padilha (2013) apontaram como dificuldades para a articulação entre AEE e ensino comum os horários de trabalho dos professores, que por necessidade aumentavam suas 
cargas-horárias de trabalho, dificultando as condições objetivas necessárias ao desenvolvimento das atividades juntos aos professores do ensino comum. Galvão e Miranda (2012) e Delpretto e Santos (2013) apontaram a ausência de planejamento para articular o trabalho da escola e do serviço do AEE. Cardoso e Tartuci (2013) identificaram que o grande número de alunos matriculados no AEE prejudicava o trabalho articulado com o ensino comum, pois o tempo se tornava insuficiente para o cumprimento das demandas.

As dificuldades destacadas acima emergem, centralmente, das condições inadequadas de organização e funcionamento do AEE que precarizam ou inviabilizam a ação pedagógica dos seus professores, resultando em sobrecarrega das atividades. Essa sobrecarga de trabalho do professor do AEE, já demarcada no acúmulo de atribuições estabelecidas nos marcos normativos (BRASIL, 2008, 2009), geralmente assumida apenas por um profissional, relaciona-se, igualmente, ao problema do grande número de alunos no AEE e à responsabilização pelos alunos com NEE vivenciada nas instituições de ensino (SANTOS, 2018). A ausência de oportunidades para realizar planejamento conjunto, também, inscreve-se como causa das dificuldades geradas entre o ensino comum e o AEE.

Os problemas apontados nas pesquisas expõem a fragilidade da integração do AEE no projeto pedagógico das escolas, bem como a fragmentação da organização didático-pedagógica que obstaculiza a possibilidade de ação colaborativa dos profissionais. De acordo com o documento A Educação Especial na Perspectiva da Inclusão Escolar: a escola comum inclusiva (BRASIL, 2010, p.19) os professores "[...] precisam se envolver para que seus objetivos específicos de ensino sejam alcançados, compartilhando um trabalho interdisciplinar e colaborativo". Práticas inclusivas exigem uma lógica colaborativa e sistêmica da gestão pedagógica da instituição de ensino capaz de engajar os segmentos da comunidade escolar e sistema educacional em proveito da educação de todos os alunos.

Dos 25 trabalhos analisados apenas 02 identificaram o contrário: Baggio (2010) verificou sólida relação entre o trabalho dos professores de ambos os ensinos na realidade pesquisada, pois os professores da sala comum afirmaram que poder contar com o apoio da professora intérprete, que auxiliava com os alunos surdos, e da professora do AEE, que auxilia outros alunos com NEE na sala de aula, melhorou o trabalho desenvolvido por eles. Também afirmaram que na falta de recursos didáticos na sala comum para atender aos alunos com NEE, os professores do AEE compartilhavam os materiais necessários existentes na SRM. Os professores participantes da pesquisa, ao serem indagados sobre a 
responsabilidade pelos alunos com NEE, concordaram que deve ser de todos, em suas diferentes funções na escola.

Cristofari, Freitas e Tezzari (2012) constataram na realidade pesquisada que professoras de ambos os ensinos avaliavam e pensavam juntas as possíveis intervenções direcionadas aos alunos com NEE matriculados na escola. Registraram o caso de um aluno com autismo infantil que a família pleiteou seu ingresso em uma escola especial. Após avaliação inicial realizada por profissional da instituição em diálogo com a professora do AEE de uma escola comum, resolveu-se que o aluno não era público-alvo da Educação Especial, resultando na matrícula dele na escola comum onde atuava a professora do AEE. Assim, para possibilitar a inclusão do aluno com autismo na escola comum, a professora do AEE criou momentos diferenciados, primeiro, na SRM, depois, na sala comum, para que ele pudesse se familiarizar na escola.

Os dois trabalhos acima registram experiências que se configuram como favoráveis à educação dos alunos com NEE, porque os professores envolvidos conferem importância ao trabalho conjunto no cotidiano de suas práticas para decidir e intervir, confirmando a colaboração entre ensino comum e AEE como estratégia pedagógica de grande impacto nos processos didáticos comprometidos com a inclusão (PACHECO; MAIA, 2017).

\section{Recursos Pedagógicos}

Associado às questões sobre as condições necessárias ao desenvolvimento do $\mathrm{AEE}$, os recursos pedagógicos ganham destaque como ferramenta imprescindível aos professores que intentam promover o acesso dos alunos com NEE ao currículo escolar. A falta de recursos pedagógicos direcionado aos alunos com NEE foi outro aspecto, apontado nas pesquisas, como impeditivo da organização do trabalho pedagógico no AEE.

Dos 25 trabalhos analisados, 05 identificaram essa problemática: Mori e Brandão (2009); Silva (2011); Galvão e Miranda (2012); Lyra (2013); Porto e Marquezine (2013). Apenas dois dos 25 trabalhos identificaram uma realidade diferenciada das que foram mencionadas pelos autores acima: Bentes (2011), ao realizar um estudo em duas instituições escolares, constatou que havia grande acervo de recursos disponíveis ao trabalho dos professores das SRM; Moreti e Corrêa (2009), por meio das observações realizadas na escola pesquisada, identificaram diversos recursos pedagógicos ao dispor do AEE, permitindo melhores condições de atuação do professor.

O AEE foi criado para apoiar pedagogicamente os alunos com NEE com fins de suprir demandas fundamentais 
à participação e à aprendizagem deles ante o currículo escolar. O AEE deve assegurar "que os alunos aprendam o que é diferente do currículo do ensino comum e que é necessário para que possam ultrapassar as barreiras impostas pela deficiência" (FIGUEIREDO, 2010, p. 33). Carência e restrição de recursos pedagógicos dificultam o atendimento individualizado e agravam as diversas barreiras existentes no ensino comum. Faz-se necessário, portanto, garantir a aquisição de recursos pedagógicos adequados, investir na ampliação, manutenção e reposição dos equipamentos e materiais disponíveis, para que se torne viável a organização e a continuidade exitosa das atividades do AEE.

\section{Avaliação dos alunos e encaminhamento ao AEE}

A avaliação é um dos pilares estruturantes da organização do ensino, porque dela decorrem os subsídios orientadores das decisões a serem tomadas pelos educadores para construírem alternativas didático-pedagógicas apropriadas à aprendizagem e ao desenvolvimento dos alunos no contexto escolar. Na PNEEPEI, a avaliação configura-se como um processo dinâmico, processual e formativo, prevalecendo os aspectos qualitativos, ressaltando o compromisso com a alteração da situação de exclusão e a importância da diversidade na promoção da aprendizagem de todos os alunos (BRASIL, 2008).

Dos 25 trabalhos analisados, 04 identificaram alguns problemas na avaliação e nos encaminhamentos dos alunos para o AEE. Chiesa (2009) identificou que muitos professores indicavam alunos para o atendimento por qualquer dificuldade na aprendizagem, como por exemplo na fala, dentre outros. Bridi (2012), por meio de entrevistas com professores do AEE de uma rede municipal, constatou que a aquisição do conteúdo escolar fazia parte das avaliações dos alunos para serem encaminhados ao AEE.

Corrêa (2013), ao analisar laudos de encaminhamentos dos alunos para o AEE na instituição pesquisada, identificou que as avaliações não apontavam as causas dos encaminhamentos com uma fundamentação pedagógica, mas muitos respaldavam-se em aspectos emocionais e comportamentais. Meletti (2009) observou nas falas dos participantes do estudo realizado que todos os alunos com problemas no comportamento expressos como hiperatividade, dificuldades de aprendizagem, entre outros, são caracterizados como público da Educação Especial.

Os problemas constatados nas pesquisas demonstram a complexidade constitutiva da prática avaliativa dos alunos com NEE e as controvertidas razões elaboradas para justificar os encaminhamentos ao AEE, tais como 
problemas emocionais, comportamentais e cognitivos. A avaliação pedagógica não pode ser reduzida ao diagnóstico clínico, como ocorre com os laudos médicos, para cumprir sua função educativa, tampouco podem ter como foco a comprovação das aquisições precárias dos conteúdos escolares e os comportamentos fora dos padrões demonstrado pelos alunos. Estes não são elementos suficientes para identificar condições específicas nos alunos como uma deficiência, para caracterizá-los como público-alvo da Educação Especial, notadamente, quando não houve uma análise criteriosa, integrada e profunda do contexto educativo.

A partir dos achados das pesquisas, entendemos que os equívocos expressos pelos professores com relação à avaliação dos alunos com NEE, podem ser repercussão da compreensão precária do papel da Educação Especial no processo de escolarização; das dúvidas sobre perspectivas, critérios e procedimentos avaliativos a serem adotados; da representação dominante centrada nas dificuldades e deficiências dos alunos, típica da visão médico-terapêutica. (SANTOS; MITJÁNS MARTÍNEZ, 2016).

$\mathrm{O}$ enfrentamento desses problemas presentes na realidade educacional requer um conjunto de reflexões e mudanças, segundo assinala Mitjáns Martínez e González Rey (2017): refletir sobre o objetivo da educação inclusiva no contexto escolar; mudar as representações dominantes, para enfatizar o aluno no processo de ensino e não suas dificuldades ou deficiências; a necessidade de um abordagem qualitativa do processo de diagnóstico e avaliação educacional; delinear estratégias educativas que considerem os vários elementos condicionantes da aprendizagem dos alunos, dentre outros.

A formação profissional (inicial e continuada) pode ajudar os professores a reverem os referenciais que fundamentam suas concepções sobre a aprendizagem dos alunos com NEE e orientam as decisões a serem tomadas na prática educativa para resolver as dificuldades expressas por eles ante os desafios lançados pelo currículo escolar.

\section{Formação Continuada de Professores}

Dos 25 trabalhos analisados, 11 identificaram a necessidade de formação continuada dos professores do AEE e da sala comum, para atuar junto aos alunos com NEE: Mori e Brandão (2009), Moreti e Corrêa (2009), Silva (2009), Baggio (2010), Lopes (2010), Silva (2011) Galvão e Miranda (2012), Fontes (2012), Sperb (2012), Lyra (2013), Machado (2013). A partir da análise dos trabalhos, entendemos que os professores percebem a falta de oferta de oportunidades formativas como um aspecto que dificulta $o$ 
processo de inclusão e que muitos têm procurado cursos de formação continuada por conta própria.

No trabalho de Baggio (2010), os professores da classe comum apontaram a falta de cursos de capacitação, como sendo uma das maiores dificuldades para trabalhar com os alunos com NEE. Chiesa (2009), no período que desenvolveu sua pesquisa, constatou que houve uma maior procura de cursos de formação continuada na área de Educação Especial por parte dos professores. Fontes (2012) identificou que os cursos ofertados pela secretaria de educação priorizavam o professor da sala de recursos multifuncionais, enquanto os professores da sala comum afirmaram que buscam, muitas vezes, formação por conta própria.

O trabalho de Mori e Brandão (2009) mostrou que mesmo os professores participando de oportunidades formativas, estas não eram suficientes para corresponder às suas demandas, pois perceberam que os cursos de formação continuada ofertados aos professores do AEE abordavam vários tipos de deficiências, o que tornava a formação desses professores generalista. Lopes (2010), por meio de entrevistas com os profissionais da escola alvo da pesquisa, percebeu que os professores da sala comum não tinham formação para trabalhar com os alunos com NEE, somente os profissionais do AEE e classe especial participavam dos cursos ofertados. Aos professores da sala comum restava o repasse de informações e experiências vivenciadas nos cursos pelos professores do AEE.

Sperb (2012) identificou a falta de conhecimento dos professores das salas comum para ensinarem os alunos surdos. Segundo os relatos dos professores intérpretes que atuavam nessas salas, os professores demonstravam desconhecer como o surdo aprende, por isto preparavam e ministravam suas aulas direcionadas somente aos alunos ouvintes. Os professores do AEE e os professores intérpretes criticaram o material do MEC direcionado à formação do professor do AEE concernente ao atendimento aos alunos surdos. De acordo com os professores, a proposta não prepara os professores para o atendimento ao aluno surdo, principalmente, quando se refere ao ensino da Língua Portuguesa. Assim, consideram que o material é confuso, incoerente, amplo e não contempla a diversidade da cultura surda. Diante disso, alguns professores afirmaram que aplicavam métodos próprios para ensinar a Língua Portuguesa aos alunos surdos e cumprir os outros objetivos curriculares.

Os elementos destacados nas pesquisas apresentadas são indicadores estratégicos sobre o processo formativo oferecido aos professores da Educação Básica pelos sistemas de ensino: a falta de formação continuada em serviço, 
apesar do aumento da demanda por formação na área de Educação Especial; a priorização da formação para os professores do AEE, em detrimento dos professores da salas comum; iniciativas individualizadas dos professores por formação na área, dentre outros. A formação continuada dos professores precisa ser repensada visto que a inclusão é uma tarefa do conjunto da escola, envolvendo todos os segmentos e funções desenvolvidas no cotidiano da prática educativa.

É importante considerar que a formação inicial, na atualidade, prepara precariamente os professores para o trabalho com os alunos com NEE. Nos cursos de licenciatura, deve-se ofertar uma disciplina voltada para área da educação especial/inclusiva e a disciplina de Língua Brasileira de Sinais (LIBRAS), o que acaba sendo insuficiente para produzir uma prática pedagógica condizente com o aparato teórico e didático exigido pelas NEE dos alunos da Educação Básica. Alguns cursos não oferecem disciplina da área de educação especial/inclusiva, sobretudo, nos cursos das licenciaturas específicas, diferente do que ocorre nos cursos de Pedagogia.

Para Mendes, Cia e Cabral (2015), existem múltiplas alternativas para promover a formação de professores voltada à construção de uma escola inclusiva: os conteúdos teóricos devem ser articulados com a realidade das escolas, maior aprofundamento dos estudos em áreas específicas da Educação Especial, integração entre as secretarias de educação e a universidade para construir as propostas formativas; socialização de experiências avaliadas como boas práticas.

Assim, faz-se indispensável que o Estado brasileiro amplie a oferta de cursos de formação continuada de forma que possa abranger todos os profissionais da escola e que essa formação seja condizente com as demandas que a realidade impõe aos professores, possibilitando criarem condições, recursos e competência para enfrentá-las.

\section{Experiências exitosas na organização e no funcionamento do AEE}

De todos os trabalhos analisados 02 produções se diferenciam das demais porque apresentaram experiências de ensino que contribuíram com o processo de inclusão de alunos com NEE, nos contextos investigados. São eles: os trabalhos de Lopes (2010) e Soares (2011). Lopes (2010) discutiu um plano de intervenção realizado durante a pesquisa, em que foram efetivadas adaptações curriculares para facilitar o desempenho acadêmico dos alunos com deficiência intelectual. O plano de intervenção foi desenvolvido com os alunos participantes da pesquisa na sala 
comum e na sala de recursos, nas áreas que eles apresentaram mais dificuldades. Na realização da proposta houve a utilização de jogos pedagógicos que estimulam o raciocínio, a atenção e a concentração, a escrita de textos espontâneos em que o aluno escrevia sobre ele mesmo. Os alunos se mostraram envolvidos com as atividades e o plano foi avaliado pelas professoras como muito positivo, pois os alunos mostraram progresso nos estudos.

Soares (2011), analisou o projeto de inclusão de Gravataí/RS, direcionado aos alunos surdos egressos da escola especial de ensino fundamental para surdos, que naquele momento entravam para o Ensino Médio em uma escola regular. O projeto propôs o AEE em todos os momentos didáticos pedagógicos frequentados pelos alunos surdos na escola, realizando, assim, diferentes formas de atendimento, momento de aulas em turmas com alunos surdos e ouvintes, outro momento das aulas em turmas separadas com professores especialistas em LIBRAS, Língua Portuguesa, e o momento do atendimento na sala de recurso multifuncional. $\mathrm{O}$ autor analisa, a partir do projeto, que este possibilitou uma maior organização da escola, envolvendo toda a comunidade escolar e possibilitando a interação entre os alunos surdos e ouvintes. A experiência investigada demonstrou que o AEE pode ser múltiplo e plural.

Os relatos de experiências apresentados nos estudos de Lopes (2010) e Soares (2011) mostram alternativas que podem ser realizadas nas escolas para contribuir com o processo de inclusão dos alunos com NEE na escola comum, mediadas pela pesquisa. O que consideramos de grande relevância no sentido de permitir visualizar possibilidades em meio a tantos desafios identificados nos demais trabalhos discutidos neste estudo. Destacamos, portanto, que a organização e funcionamento do AEE na escola pode ser repensada a partir de diferentes formas de atendimento nas várias situações e espaços em que possam ser desenvolvidas atividades didáticas, contando com a participação de diferentes agentes educativos.

\section{Considerações Finais}

Este estudo teve como objetivo compreender a organização do trabalho pedagógico do AEE, por meio da análise das produções acadêmicas brasileiras. Os estudos mapeados contribuíram para a compreensão da organização do trabalho pedagógico do AEE e o desenvolvimento de sua prática nas escolas brasileira, pois os estudos analisados são investigações realizadas em diferentes estados e municípios do país, tais como: Cristalina - GO, Campo Grande - MS; Belém - PA; Florianópolis - SC; Gravataí RS; Londrina - PR e São Paulo - SP. 
Os estudos mapeados identificaram muitos aspectos na organização do AEE que implicaram no seu funcionamento e em sua qualidade compatíveis com as definições presentes nos marcos regulatórios do serviço. Dentre os aspectos identificados destacamos, de modo geral, algumas dificuldades presentes nas práticas analisadas na pesquisas, que se constituem como barreiras ao trabalho do AEE e, consequentemente, à inclusão escolar: alunos com diferentes tipos de deficiência participavam do AEE no mesmo horário do ensino comum, contrariando as orientações legais e restringindo o acesso ao currículo escolar; a falta de formação dos profissionais da escola; a falta de equipamentos e materiais pedagógicos, que deem conta das demandas específicas de aprendizagem dos alunos; a falta de apoio dos vários segmentos das instituições escolares; a falta de articulação entre ensino comum e AEE.

Por outro lado, foi possível identificar problemas relacionados diretamente às atribuições da gestão dos sistemas de ensino e à gestão pedagógica da escolas que podem favorecer a organização e o funcionamento do AEE, como por exemplo, a resistência de alguns professores ao trabalho do professor do AEE e a responsabilização desse professor com vistas à escolarização dos alunos com NEE; a falta de planejamento capaz de inscrever efetivamente o AEE na proposta pedagógica da escola, bem como a sua fragmentação que inviabiliza as condições necessárias à articulação entre os professores; a falta de acompanhamento pedagógico; a grande quantidade de alunos encaminhados para o AEE em virtude de falhas na avaliação que, facilmente, convertem as manifestações diferenciadas de aprendizagem, comunicação e comportamento dos alunos em dificuldades que devem ser assumidas pelo serviço.

Esses são aspectos que a instituição escolar pode dialogar e negociar com os segmentos da comunidade, sobretudo, com o corpo docente e profissionais de apoio existentes na elaboração e na assunção de alternativas colaborativas de enfrentamento dos problemas apontados. No entanto, entende-se também que as resoluções necessárias extrapolam o âmbito da escola, pois são diretrizes oriundas dos sistemas de ensino como expressão das políticas e legislações afinadas com a cultura do desempenho, típica do produtivismo e tecnicismo predominantes na educação brasileira nos últimos anos, como as avaliações externas em larga escala (MENDES; CIA; D'AFFONSECA, 2015; SANTOS, 2018; FREITAS, 2018). Essa perspectiva engessa e restringe a organização do trabalho pedagógico da escola que produz condições de ensino homogeneizadoras, meritocráticas e seletivas profundamente contraditórias com os princípios da educação inclusiva.

O estudo em tela também identificou algumas práticas e ações favoráveis que contribuíram para o processo 
de inclusão dos alunos com NEE no ensino regular, como por exemplo: as adaptações curriculares que podem ser uma alternativa viável para o trabalho direcionado aos alunos com deficiência intelectual, possibilitando o acesso ao currículo escolar e a importância da parceria entre os professores da sala comum e AEE para o enriquecimento das ações pedagógicas desenvolvidas no âmbito do AEE, articulação crucial ao processo de inclusão escolar dos alunos com NEE.

Diante disso, considera-se que foram identificados mais aspectos desafiantes do que favoráveis à organização adequada e ao bom funcionamento do AEE. A organização distancia-se das diretrizes legais existentes, pois faltam ações dos governos nos diferentes níveis da administração pública para ampliar a oferta de salas de recursos multifuncionais, garantir formação continuada aos professores, materiais e recursos para o trabalho do AEE e, principalmente, repensar a organização do trabalho pedagógico da escola ainda calcada em um projeto de educação excludente, para que sejam viáveis, de fato, as garantias previstas na legislação e políticas voltadas à ratificação dos direitos dos alunos com NEE.

Portanto, diante do estudo realizado, concluímos que, nas realidades investigadas, apesar das dificuldades mencionadas vinculadas ao AEE, também existem posturas e ações de resistência e luta expressas na busca cotidiana de reinvenção das práticas educativas, por meio de novas alternativas relacionais e pedagógicas, mesmo sendo específicas de algumas instituições e/ou alguns profissionais. A ampliação da resistência e da luta pela garantia da democratização da educação pública e a efetivação de processos de ensino mais inclusivos ajudam a tecer, no presente, a transformação da educação em emancipatória e de qualidade social.

\section{Referências}

BRASIL. Constituição da República Federativa do

Brasil. Brasília: Imprensa Oficial, 1988.

. Congresso Nacional. Lei no 9.394, de 20 de dezembro de 1996. Estabelece as diretrizes e bases da educação nacional. Brasília, DF, 1996.

Política Nacional de Educação Especial

na Perspectiva da Educação Inclusiva. Secretaria de Educação Especial - MEC/SEESP, 2008.

Decreto 6.571, de 17 de setembro

de 2008. Dispõe sobre o atendimento educacional 
especializado, regulamenta o parágrafo único do Art. 60 da Lei $\mathrm{N}^{0}$. 9.394, de 20 de dezembro de 1996, e acrescenta dispositivo ao Decreto No. 6.253, de 13 de novembro de 2007. Secretaria de Educação Especial - MEC/SEESP, 2008.

Resolução no . 4, de 2 de outubro de 2009. Institui as Diretrizes Operacionais para o Atendimento Educacional Especializado na Educação Básica, na modalidade Educação Especial. Conselho Nacional de Educação/ Câmara de Educação Básica - MEC/SEESP, 2009.

. Ministério da Educação. Secretaria de Educação Especial. A Educação Especial na Perspectiva da Inclusão Escolar: a escola comum inclusiva. Brasília, DF: MEC, 2010.

BARbOSA, Meiriene Cavalcante. Do preferencial ao necessário: $o$ atendimento educacional especializado na escola comum. 2012. 174 f. Dissertação (Mestrado em Educação) - Programa de Pós-Graduação em Educação, Universidade Estadual de Campinas, Campinas, 2012.

BAGGIO, Sandra Santos Rocha. Implementação da educação inclusiva em uma escola no município de Cristalina-Go. 2010. 95 f. Dissertação (Mestrado em Teologia) - Programa de Pós-Graduação em Teologia, Escola Superior de Teologia, São Leopoldo, 2010.

BENTES, Nilda de Oliveira. Educação no contraturno: oferta especializada para estudantes com necessidades educacionais especiais. In: Congresso Brasileiro Multidisciplinar De Educação Especial, 6., 2011, Londrina. Anais... Londrina/Paraná: Universidade Estadual de Londrina/UEL, 2011. Disponível em: <www.uel.br/eventos/congressomultidisciplinar/pages/publicação-de-anais/anais 2011.php>.

BRIDI, Fabiane Romano de Souza. A produção diagnóstica de alunos com deficiência mental no contexto do atendimento educacional especializado. In: $35^{\text {a }}$ Reunião Anual da ANPED. Anais... Porto de Galinhas/Pernambuco. 2012. Disponível em: <35reuniao.anped.org.br >.

CARDOSO, Camila Rocha; TARTUCI, Dulcéria. O funcionamento do atendimento educacional especializado nas salas de recursos multifuncionais e a atuação docente. In: CONGRESSO BRASILEIRO MULTIDISCIPLINAR DE EDUCAÇÃO ESPECIAL, 7., 2013, Londrina. Anais... Londrina/Paraná: Universidade Estadual de Londrina/ UEL, 2013. Disponível em: <www.uel.br/eventos/congressomultidisciplinar/pages/publicação-de-anais/anais 2013.php $>$. 
CHRISTOFARI, Ana Carolina; FREITAS, Cláudia Rodrigues; TEZZARI, Mauren Lúcia. Educação infantil e ensino fundamental: interlocuções com o atendimento educacional especializado. In: 35 a Reunião Anual da ANPED. Anais... Porto de Galinhas/Pernambuco. 2012. Disponível em: <35reuniao.anped.org.br $>$.

CHIESA, Marilei. Implantação do atendimento educacional especializado na rede municipal de ensino de pelotas sob a perspectiva da educação ambiental. 2009. 111 f. Dissertação (Mestrado em Educação Ambiental) - Programa de Pós-Graduação em Educação Ambiental, Universidade Federal do Rio Grande, Rio Grande, 2009.

CORRÊA, Thaiza de Carvalho. Avaliação, diagnóstico e encaminhamento de crianças com necessidades educacionais especiais no sistema municipal de ensino de Londrina - PR. 2013. 122 f. Dissertação (Mestrado em Educação) - Programa de Mestrado em Educação, Universidade Estadual de Londrina, Londrina, 2013.

DUTRA, Claudia Pereira; SANTOS, Martinha Clarete Dutra. Os rumos da educação especial no Brasil frente ao paradigma da educação inclusiva. Inclusão: revista da educação especial / Secretaria de Educação Especial. v. 5, n. 1 (jan./jul.) - Brasília: Secretaria de Educação Especial, 2010.

DELPRETTO, Bárbara Martins de Lima; SANTOS, Bianca Campos Carlos. Um contexto em transformação político-pedagógico: a articulação entre uma escola regular e um centro de atendimento educacional especializado. Revista Educação Especial, Santa Maria, v. 26, n. 47, p. 727-742, set./dez. 2013.

DELEVATI, Aline de Castro. AEE: que atendimento é este? as configurações do atendimento educacional especializado na perspectiva da rede municipal de ensino de Gravataí/RS. 2012. 143 f. Dissertação (Mestrado em Educação) - Programa de Pós-Graduação em Educação, Universidade Federal do Rio Grande do Sul, Porto Alegre, 2012.

FIGUEIREDO, Rita Vieira. Incluir não é inserir, mas interagir e contribuir. Inclusão: revista da educação especial / Secretaria de Educação Especial. v. 5, n. 1, jan/jul - Brasília: Secretaria de Educação Especial, 2010.

FONTES, Diana Campos. Atendimento educacional especializado: um estudo de caso. 2012. 148 f. Dissertação 
(Mestrado em Psicologia) - Programa de Pós-Graduação em Psicologia, Universidade Federal de Rondônia, Porto Velho, 2012.

FREITAS, Luiz Carlos de. A reforma empresarial da educação: nova direita, velhas ideias. São Paulo: Expressão Popular, 2018.

GALVÃO, Nelma de Cássia Silva Sandes; MIRANDA, Theresinha Guimarães. Atendimento educacional especializado para alunos com surdocegueira: um estudo de caso no espaço da escola regular. Revista Brasileira de Educação Especial, v.19, n.1, p.43-60, 2012.

GERHARDT, Tatiana Engel; SILVEIRA, Denise Tolfo. Métodos de Pesquisa. Porto Alegre: Editora da UFRGS, 2009.

GLAT, Rosana; FERNANDES, Edicléa Mascarenhas. Da educação segregada à educação inclusiva. Inclusão: revista da educação especial / Secretaria de Educação Especial. v.1, n.1 - Brasília: Secretaria de Educação Especial, 2005.

LOPES, Esther. Adequação curricular: um caminho para a inclusão do aluno com deficiência intelectual. 2010. 168 f. Dissertação (Mestrado em Educação) - Programa de Mestrado em Educação, Universidade Estadual de Londrina, Londrina, 2010.

LYRA, Juliana Chueire. Atendimento educacional especializado de alunos com altas habilidades/superdotação na cidade de Londrina, Paraná: um estudo de caso. 2013. 149 f. Dissertação (Mestrado em Educação) - Programa de mestrado em Educação, Universidade Estadual de Londrina, Londrina, 2013.

MACHADO, Rosângela. O atendimento educacional especializado (AEE) e sua repercussão na mudança das práticas pedagógicas, na perspectiva da educação inclusiva: um estudo sobre as escolas comuns da rede municipal de ensino de Florianópolis/SC. 2013. 185 f. Tese (Doutorado em Educação) - Programa de Pós-Graduação em Educação, Universidade Estadual Campinas, Campinas, 2013.

MENDES, Enicéia Gonçalves; CIA, Fabiana; D’AFFONSECA, Sabrina Mazo (Orgs). Inclusão escolar e a avaliação do público-alvo da Educação Especial. São Carlos: Marquezine \& Manzini: ABPEE, 2015. 
; CIA, Fabiana; CABRAL, Leonardo Santos Amâncio (Orgs.). Inclusão escolar e os desafios da formação de professores Educação Especial. São Carlos: Marquezine \& Manzini: ABPEE, 2015.

MELETTI, Silvia Márcia Ferreira. A inclusão de alunos com necessidades educacionais especiais no sistema regular de ensino no município de Londrina. In: $32^{\mathrm{a}}$ Reunião Anual da ANPED. Anais... Caxambu/Minas Gerais. 2009. Disponível em: <32reuniao.anped.org.br $>$.

MENEZES, Ebenezer Takuno de; SANTOS, Thais Helena dos. Verbete Declaração de Salamanca. Dicionário Interativo da Educação Brasileira - Educabrasil. São Paulo: Midiamix, 2001.

MILANESI, Josiane Beltrame. Organização e funcionamento das salas de recursos multifuncionais em um município paulista. 2012. 183 f. Dissertação (Mestrado em Educação Especial) - Programa de Pós-Graduação em Educação Especial, Universidade Federal de São Carlos, São Carlos, 2012.

MITJÁNS MARTÍNEZ, Albertina; GONZÁLEZ REY, Fernando Luis. Psicologia, educação e aprendizagem escolar: avançando na contribuição da leitura cultural-histórica. São Paulo: Cortez, 2017.

MORI, Nerli Nonato Ribeiro; BRANDÃO, Silvia Helena Altoé. $\mathrm{O}$ atendimento em salas de recursos para alunos com altas habilidades/superdotação: o caso do Paraná. Revista Brasileira de Educação Especial, v.15, n.3, 2009.

MORETI, Ivete Goldoni; CORRÊA, Nesdete Mesquita. A sala de recursos como atendimento educacional especializado para a inclusão de alunos com deficiência mental em classes comuns. In: Congresso Brasileiro Multidisciplinar de Educação Especial, 5., 2009. Londrina. Anais... Londrina/ Paraná: Universidade Estadual de Londrina/UEL, 2009. Disponível em: <www.uel.br/eventos/congressomultidisciplinar/pages/publicação-de-anais/anais 2009.php >.

NÓBREGA, Paulo Henrique. Levantamento do perfil da mão-de-obra da construção civil de foz do Iguaçu com ênfase em treinamento. 2006. 135 f. Monografia (Conclusão do Curso de Engenharia Civil). União Dinâmica de Faculdades Cataratas. Foz do Iguaçu, 2006.

PORTO, Patrícia Padilha; MARQUEZINE, Maria Cristina. $\mathrm{O}$ atendimento educacional especializado em sala de recursos multifuncional. In: Congresso Brasileiro Multidisciplinar 
de Educação Especial, 7., 2013, Londrina. Anais... Londrina/Paraná: Universidade Estadual de Londrina/UEL, 2013. Disponível em: <www.uel.br/eventos/congressomultidisciplinar/pages/publicação-de-anais/anais 2013.php >.

PACHECO, Ana Paula; MAIA, Helenice. O trabalho do professor do atendimento educacional especializado em salas de recursos multifuncionais em escolas da Baixada Fluminense. Revista Educação e Cultura Contemporânea. v. 14, n. 35, p. 194-213, abr/jun., 2017. Disponível em: http://periodicos.estacio.br/index.php/reeduc/article/ viewArticle/3557. Acesso em: 12 jun. 2018.

PADILHA, Adriana Cunha. O trabalho de professores de educação especial: análise sobre a profissão docente no Estado de SP. In: $36^{\text {a }}$ Reunião Nacional da ANPED. Anais... Goiânia/Goiás. 2013. Disponível em: < 36.reuniao.anped. org.br >. Acesso em: 29 jan. 2014.

SASSAKI, Romeu Kazumi. Inclusão: o paradigma do século 21. Inclusão: Revista Da Educação Especial / Secretaria De Educação Especial. v.1, n.1 - Brasília: Secretaria De Educação Especial, 2005.

SANTOS, Geandra Claudia Silva. Educação Especial Inclusiva: Desafios persistentes, ameaças emergentes e lutas que se renovam. In: ARAÚJO, E. J. M.; FARIAS, M. da S. B. de; GUERRA, Maria das Graças Gonçalves Vieira (Orgs.). Políticas Públicas da Educação Superior: Gestão, Avaliação e Financiamento. João Pessoa: Editora da UFPB, v. 1, 2018.

; MITJÁNS MARTÍNEZ, Albertina. A Subjetividade social da escola e os desafios da inclusão de alunos com desenvolvimento atípico. Rev. Bras. Ed. Esp. Marília, v. 22, n. 2, p. 253-268, abr/jun., 2016.

SILVA, Rosana Sebastião. Sala de recursos como apoio especializado a alunos com necessidades educacionais especiais: um estudo em escolas estaduais. 2009. 101 f. Dissertação (Mestrado em Distúrbios do Desenvolvimento). Universidade Presbiteriana Mackenzie, São Paulo, 2009.

SILVA, Fabrícia Gomes. Inclusão escolar de alunos com deficiência intelectual: $o$ atendimento educacional especializado (AEE) em discussão. 2011. 166 f. Dissertação (Mestrado em Educação) - Centro de Educação Mestrado Acadêmico em Educação, Universidade Estadual do Ceará, Fortaleza, 2011. 
SPERB, Carolina Comerlato. O ensino da língua portuguesa no atendimento educacional especializado para surdos. 2012. 137 f. Dissertação (Mestrado em Educação) - Programa de Pós-Graduação em Educação, Universidade Federal do Rio Grande do Sul, Porto Alegre, 2012.

SOARES, Carlos Henrique Ramos. Inclusão, surdez e ensino médio: perspectivas e possibilidades para o atendimento educacional especializado. 2011. 96 f. Dissertação (Mestrado em Educação) - Programa de Pós-Graduação em Educação, Universidade Federal do Rio Grande do Sul, Porto Alegre, 2011.

TEIXEIRA, Célia Regina. O "estado da arte”: a concepção de avaliação educacional veiculada na produção acadêmica do programa de pós-graduação em educação: currículo (1975-2000). Cadernos de Pós-Graduação- educação. São Paulo, v.5, n.1, p.59-66, 2006.

Recebido em: 20-12-2018 Aprovado em: 14-05-2020 Publicado em: 22-05-2020 